\title{
THE INFLUENCE OF ALLOY CHEMISTRY AND POWDER PRODUCTION METHODS ON POROSITY IN A P/M NICKEL-BASE SUPERALLOY
}

\author{
Eric S. Huron (*) \\ Rebecca L. Casey (\#) \\ Michael F. Henry (\#) \\ David P. Mourer (@) \\ * - General Electric Aircraft Engines, Cincinnati, OH, 45215 \\ \# - General Electric Corporate Research \& Development, \\ Schenectady, NY, 12345 \\ @- General Electric Aircraft Engines, Lynn, MA, 01910
}

\begin{abstract}
Advanced nickel-base superalloys for use in gas turbine engines are produced using powder metallurgy $(\mathrm{P} / \mathrm{M})$ processing. The high alloy content of these alloys typically results in a high solvus temperature for the strengthening gamma-prime $\left(\gamma^{\prime}\right)$ phase and so the heat treatment must be carried out at high temperature. This can allow entrapped gas from the atomization process to form Thermally Induced Porosity (TIP) with negative impact on low cycle fatigue.

A designed experiment was undertaken to investigate chemistry and atomization parameters on porosity. The alloy used was the advanced alloy KM4 (U. S. Patent 5,143,563), which contains about 54 volume fraction of $\gamma^{\prime}$ and has a $\gamma^{\prime}$ solvus of about $1170^{\circ} \mathrm{C}$. The variables studied included carbon, boron, superheat, mesh size, and gas:metal (G:M) ratio.

In general, atomization parameters influenced loose powder porosity, with some secondary influence on TIP, while composition parameters influenced TIP and had little influence on loose powder porosity. Increased levels of boron strongly increased the amount of TIP but only slightly impacted loose powder porosity. Carbon had negligible impact on either type of porosity. Lower levels of loose powder porosity were associated with lower superheat, increased gas:metal ratio, finer powder size distributions, and reduced metal flow rate. Some of the responses were interactive. For example, higher metal flow rate promoted coarse mesh distributions.
\end{abstract}

The different levels of influence on loose powder porosity versus TIP appeared to be due to different mechanisms. For boron, which impacts TIP but not loose powder porosity, the apparent mechanism was that boron impacted grain boundary strength or promoted local incipient melting. For the atomization parameters which influence loose powder porosity, the apparent mechanism was a change in how much entrapped gas was retained during formation of the powder particles. The results are discussed in terms of significance for alloy development and process development.

\section{Superalloys 1996}

Edited by R. D Kissinger, D. J. Deye, D. L. Anton,

Edited by R. D. Kissinger, D. Deye, D. L. Anton,
A. D. Cetel, M. V. Nathal, T. M. Pulluck, anu D. A. Woodford

The Minerals, Metals \& Materials Society, 1996

\section{INTRODUCTION}

This experimental program studied factors controlling Thermally Induced Porosity (TIP) in powder metallurgy (P/M) alloys. It was actually the byproduct of a study intended to determine the influence of minor element chemistry on properties and processing of KM4, an advanced P/M disk alloy ${ }^{1}$ developed for the Dual Alloy Disk (DAD) program ${ }^{2}$. Powder heats with various boron and carbon levels were produced at GE Corporate Research \& Development Center (CRD) in Schenectady, New York, and were subjected to a variety of consolidation routes. An unusual amount of porosity was noted in many of the extrusions. The atomization parameters had been varied during the runs to support a concurrent fundamental atomization parameter vs. yield program, with the assumption that changes in those parameters would have little effect on the final powder. The initial data review indicated that this assumption had been wrong; in fact, the atomization parameters had a strong impact on porosity. Since the existing matrix of runs did not allow separation of chemistry impacts versus atomization impacts, an expanded matrix was developed, evolving into a core eight-run (L8) Designed Experiment with high and low levels of superheat, flow rate, and boron level. The L8 experiment, combined with the initial runs and several additional supporting runs, provided a range of data allowing a more complete assessment of what factors impacted porosity.

The results suggested that both alloy chemistry and atomization had major influences on both loose powder porosity and on TIP. The results are discussed in terms of possible mechanisms and practical impact on alloy design, powder production, and component fatigue life

\section{PROCEDURE}

Multiple powder runs were produced from alloy $\mathrm{KM} 4{ }^{1}$. The nominal composition for the base alloy and the minor element variations studied are shown in Table 1 . The product of each heat was screened to $-140 /+200,-200 /+270$, and -270 mesh cuts.

The powder was produced using a pilot scale atomization facility at the General Electric Corporate Research \& Development 
Table 1: Compositions for Initial KM4 Modification Heats (w/o)

\begin{tabular}{|c|c|c|c|}
\hline \multicolumn{4}{|c|}{$\begin{array}{l}\text { base composition: } \\
\text { Wi }-18 \mathrm{CC}-12 \mathrm{Cr}-4 \mathrm{MO}-4 \mathrm{AL}-4 \mathrm{TI} \\
-2 \mathrm{Nb}-0.0302 \mathrm{r}-0.030 \mathrm{~B}-0.030 \mathrm{C}\end{array}$} \\
\hline \multicolumn{4}{|c|}{ minor el ement variations: } \\
\hline Designation & Chemistry & Heat Numb & \\
\hline base $\mathrm{KMH}$ & $0.030 \mathrm{~B}-0.030 \mathrm{C}$ & T858 & \\
\hline $1-\mathrm{KN} / 4$ & $0.015 B-0.015 C$ & 1860 & \\
\hline $2-\mathrm{x} M / 4$ & $0.015 B-0.040 C$ & 1850 & \\
\hline 3-KMH & $0.015 B=0.065 c$ & I852 & \\
\hline 4-KM4 & $0.0008=0.040 c$ & T851 & \\
\hline $5-K M 4$ & $0.015 B-0.040 C$ & 1853 & (a) \\
\hline $6-\mathrm{KN}+4$ & $0.0308-0.040 C$ & T854 & \\
\hline $7-\mathrm{kmm}$ & $0.015 B-0.040 c$ & 1861 & (b) \\
\hline $6-x \times 4$ & $0.0308-0.040 c$ & T882 & (c) \\
\hline 4-KN4 & $0.0008-0.040 c$ & 1882 & (d) \\
\hline
\end{tabular}

notes: a) dupl icates 2-kM4

b) nitrogen atomization

c) remake of 6-KM44 at T851 conditions

d) remake of 4-KM4 at T882 conditions

Center in Schenectady, New York. The powder heats were typically $10-15 \mathrm{~kg}$ in size. Charge material for the powder facility was prepared using Vacuum Induction Melted (VIM) ingots. The nominal $16 \mathrm{~kg}$ ingots were sandblasted and cropped to remove surface oxides and provide an ingot shape compatible with the atomizer.

The detailed layout and operation of this facility have been previously described elsewhere ${ }^{3}$. A $40 \mathrm{~kW}$ induction powder supply was used to heat the metal. Typical superheats were $200^{\circ} \mathrm{C}$ although some nuns were performed at $50^{\circ} \mathrm{C}$ as part of the experimental design. Nominal melt flow rates were in the 2.2-4.5 $\mathrm{kg} / \mathrm{min}$ range coupled with nominal gas flows of $18-27 \mathrm{~kg} / \mathrm{min}$. Powder was separated from the exiting gas flow via a cyclone. Once cooled, the powder was removed from the system (exposing the powder to air) and transferred to the sieving operation.

The initial experimental runs mixed variation in boron and carbon with variation in atomization technique indiscriminately, on the assumption that the atomization studies would not impact the quality of the powder, only the powder yield. The wide variations in porosity actually observed proved to be impossible to separate on the basis of atomization versus chemistry influence. Additional runs were added understand the effects. First, the two runs at the highest and lowest boron levels were repeated with the atomization conditions interchanged (Table 1), and eventually more runs were added to arrive at the experimental design shown in Table 2. The core Designed Experiment was a $2^{3}$ design (three variables at two levels each, requiring eight runs) which included controlled boron, superheat, and flow rate levels to clearly distinguish effects. Another variable could have been added to make a $2^{(4-1)}$ partial factorial with only a slight increase in experimental noise, but the variables considered as fourth variables (particularly atomization chamber pressure) were likely to interact with the set-up parameters for the flow rate and superheat. One run was produced using nitrogen atomization gas to investigate a potential benefit in reduccd TIP.
Table 2: Atomization Runs for L8 Designed Experiment

\begin{tabular}{|c|c|c|c|c|c|}
\hline \multirow{2}{*}{\multicolumn{2}{|c|}{ Run\# }} & \multicolumn{3}{|c|}{ Variables 3 at 2 levels $=2^{3}$} & \multirow[b]{2}{*}{$\begin{array}{l}\text { Resulting } \\
\text { Nozzle } \\
\text { Pressure } \\
\text { Aim / Actual } \\
\text { (bar) }\end{array}$} \\
\hline & & Boron & $\begin{array}{l}\text { Melt Flow Rate } \\
\text { Aim / Actual } \\
\text { (kq/min) }\end{array}$ & $\begin{array}{c}\text { Superheat } \\
\text { Aim } \\
\text { (C) } \\
\end{array}$ & \\
\hline 1 & $T-884$ & 0.030 & $>18 / 27.7$ & $50 \mathrm{C}$ & $37.4 / 33.5$ \\
\hline 2 & $T-854 *$ & 0.030 & $>18 / 30.8$ & $200 C^{\star}$ & $37.4 / 30.6$ \\
\hline 3 & $T-885$ & 0.030 & $<4.5 / 3.5$ & $50 \mathrm{C}$ & $23.8 / 23.8$ \\
\hline 4 & $T-886$ & 0.030 & $<4.5 / 3.6$ & $200 \mathrm{C}$ & $23.8 / 23.8$ \\
\hline 5 & $T-888$ & 0.015 & $>18 / 18.8$ & $50 \mathrm{C}$ & $37.4 / 30.6$ \\
\hline 6 & $T-889$ & 0.015 & $>18 / 27.5$ & $200 \mathrm{C}$ & $37.4 / 31.3$ \\
\hline 7 & $T-890$ & 0.015 & $<4.5 / 2.1$ & $50 \mathrm{C}$ & $23.8 / 17.0$ \\
\hline 8 & $T-891$ & 0.015 & $<4.5 / 3.9$ & $200 \mathrm{C}$ & $23.8 / 23.8$ \\
\hline & $T-882 a$ & 0.030 & $11 / 11.5$ & $200 \mathrm{C}$ & $20.4 / 37.4$ \\
\hline 10 & $r-887$ & 0.030 & $11 / 16.7$ & $200 \mathrm{C}$ & $20.4 / 22.9$ \\
\hline
\end{tabular}

Notes: * this run in Dofe assumed to exist as T-854

a this run in DofE assumed to exist as $T-882$

Atomization chamber pressure was considered as an additional variable but it could not be independently well controlled in high and low gas and melt flow rate experiments. The atomizer chamber was such that pressure built up from an initial value slightly over atmospheric pressure (about 1.1 bar) until the exhaust system released some pressure in the atomization tower during the runs, especially for the high melt flow rate runs. This was due to limited exhaust capability of the atomizer and the fact that high melt flows were coupled with high gas flows to maintain appropriate gas-to-metal ratios ( $\mathrm{G} / \mathrm{M}$, or weight of gas per weight of metal, both per unit time). Hence all powder made at the high flow rates was atomized into an elevated pressure atmosphere (up to 1.5 bar greater than the low melt flow rate runs).

Powder was consolidated using either hot compaction plus hot extrusion or Hot Isostatic Pressing (HIP). The extrusion cans were fabricated as shown in Figure 1 from 300 series stainless steel. After filling a vacuum was slowly pulled on the cans, and held for a minimum time of $\mathbf{4 8}$ hours at room temperature. The vacuum level was stabilized at 0 microns with a maximum leakup rate of 5 microns in 15 minutes. The cans were then heated to $200^{\circ} \mathrm{C}$ and held under vacuum for 16 additional hours. The can stems were heated and pinched off at the end of the outgassing cycle and the pinched tubing was welded shut.

The extrusion cans were consolidated using a two-step process of hot compaction plus extrusion. Compaction was done at $1038^{\circ} \mathrm{C}$ after a four hour preheat into a blind die. The compactions were pushed into carbon steel sleeves placed in the liner (with copious lubricant) so that after compaction the extrusions could be processed in the same liner without remachining by simply removing the sleeves. Extrusion was done at $1049^{\circ} \mathrm{C}$ using the nominal $8.5 \mathrm{~cm}$ compacted can diameter can after compaction within a $9.05 \mathrm{~cm}$ liner, through a $3.68 \mathrm{~cm}$ die

The HIP cans are shown in Figure 2. The HIP cans were produced using a standard procedure of cold evacuation for 36 hours minimum to a vacuum of 5 microns or better with a maximum leakup rate of $0.25 \mathrm{microns} /$ minute or $15 \mathrm{microns} / \mathrm{hour}$. This was followed by can heating to $550^{\circ} \mathrm{C}$ for at least 48 hours 


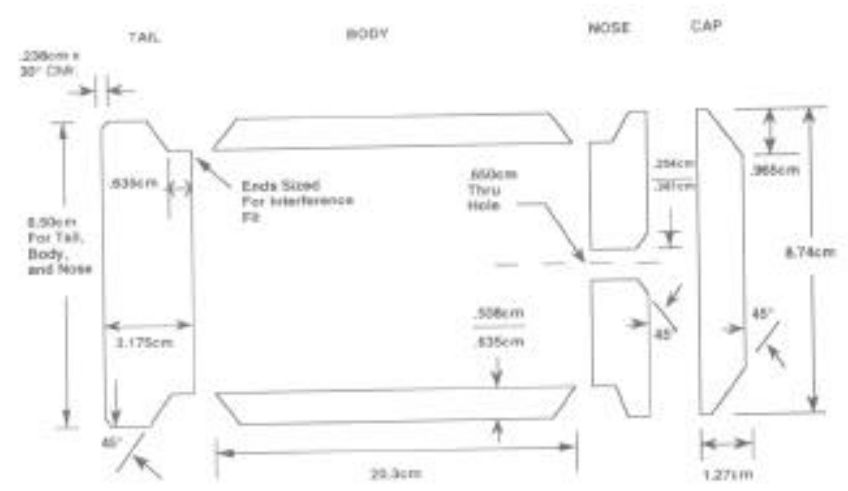

Figure 1: Extrusion can design

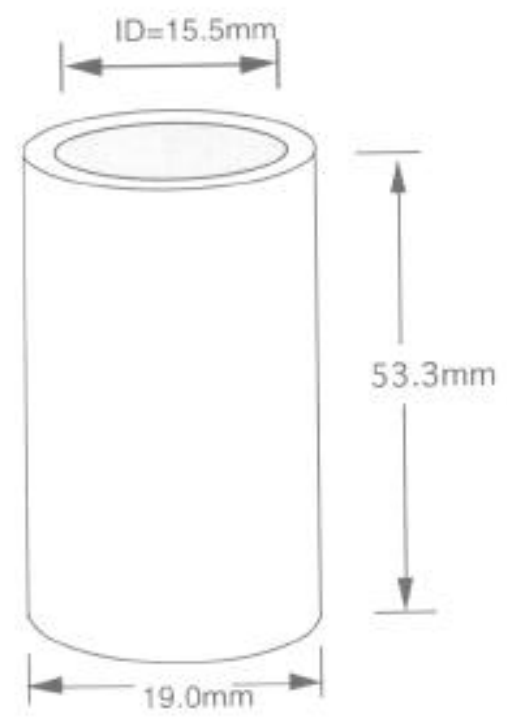

Figure 2: HIP can design

to a vacuum level of 5 microns or better with a maximum leakup rate of 0.25 microns/minute.

To provide material for LCF testing, additional extrusions were processed by Cameron Forge (now Wyman-Gordon). Extrusion cans of nominal $25 \mathrm{~cm}$ length $\times 9 \mathrm{~cm}$ dia. were produced from 304 stainless steel. The cans were evacuated with a cold static degas cycle. The cans were pumped down to a minimum aim vacuum level of approximately 10 microns with a leakup rate of about 3-7 microns/ minute. The cans were hot compacted and extruded using a 2500 -ton laboratory press. Compaction was performed at $1038^{\circ} \mathrm{C}$ and extrusion was performed at $1043^{\circ} \mathrm{C}$ with a $5.5: 1$ reduction ratio and a $100 \mathrm{~cm} /$ minute ram speed

A loose powder porosity evaluation procedure developed at CRD was key to successful data interpretation. The powder was sieved to appropriate size fractions and mounted by vacuum impregnation in epoxy. The mount was polished and three $200 \mathrm{X}$ micrographs were taken. The largest particle diameter from all three pictures was measured (this particle was assumed to be sectioned at mid-plane). Particle diameters that fell within a $10 \%$ tolerance of the diameter were counted. Next, those particles that fell within that counted population that contained pores or voids, of any size or shape, were counted (Figure 3). Typical values were on the order of $10-20$ pores in 40-70 particles.

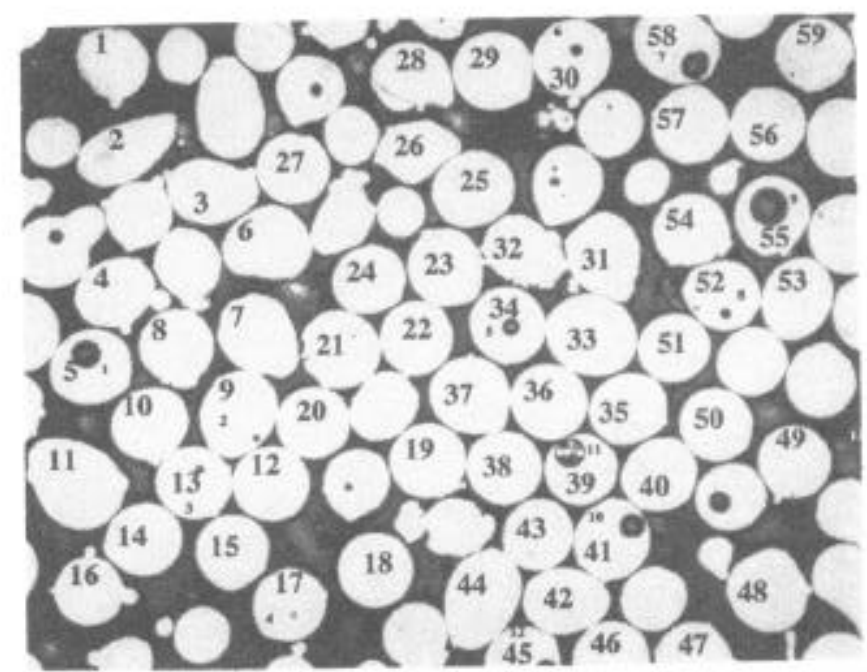

Figure 3: Schematic of pore counting measurement technique. Only particles with a diameter on the plane of polish within a tolerance range were included in the analysis. In this example, 12 particles with pores were counted in a total of 59 particles.

A density measurement procedure ${ }^{4}$ for bulk consolidated material developed at CRD was another key to the success of this study. The procedure used the Archimedian principle of comparing the weight of the test sample in air vs. a liquid of known density, calibrated against parallel measurements using a solid of known density. Improved controls of the liquid temperature, surface finish of the sample (to control surface bubbles) and the use of an immersion fixture designed to minimize the impact of surface tension allowed high accuracy and precision. HIP'ed and extruded coupons were heat treated at a variety of temperatures for four hour exposures to examine TIP as a function of chemistry, atomization, and exposure. The material was evaluated metallographically and via'the density procedure in the as-consolidated form and after TIP exposure. The baseline exposure condition was $1204^{\circ} \mathrm{C} / 4 \mathrm{hrs}$ in an air furnace.

Limited low cycle fatigue (LCF) testing using the original CRD extrusions was performed. Alloys 3-KM4, 4-KM4, and 7-KM4 were included to see if either reduction of boron or $\mathrm{N}_{2}$ atomization could eliminate the negative impacts of TIP. Sections of the extrusions were supersolvus solution heat treated at $1190^{\circ} \mathrm{C}$ and air cooled to give a cooling rate estimated at $111^{\circ} \mathrm{C} / \mathrm{min}$, then aged at $760^{\circ} \mathrm{C}$ for 8 hours. LCF bars were machined from the extrusion. An LCF specimen with a nominal gage section of $0.64 \mathrm{~cm}$ diameter by $1.91 \mathrm{~cm}$ long were used. Standard strain control procedures were used with a strain range of $0.80 \%$ at $649^{\circ} \mathrm{C}$ used as the test condition. Tests were run in strain control at $30 \mathrm{cpm}$ for the first 24 hours of testing (about 43000 cycles), then in load control at $300 \mathrm{cpm}$ to failure

\section{RESULTS}

After sorting through some of the confounding influences, several key lessons concerning alloy chemistry and atomization influences were learned. The overall observation was that alloy chemistry (chiefly boron) impacted TIP porosity while several atomization parameters impacted loose powder porosity. The full data are given in Table 3 , but the results can be more clearly understood 

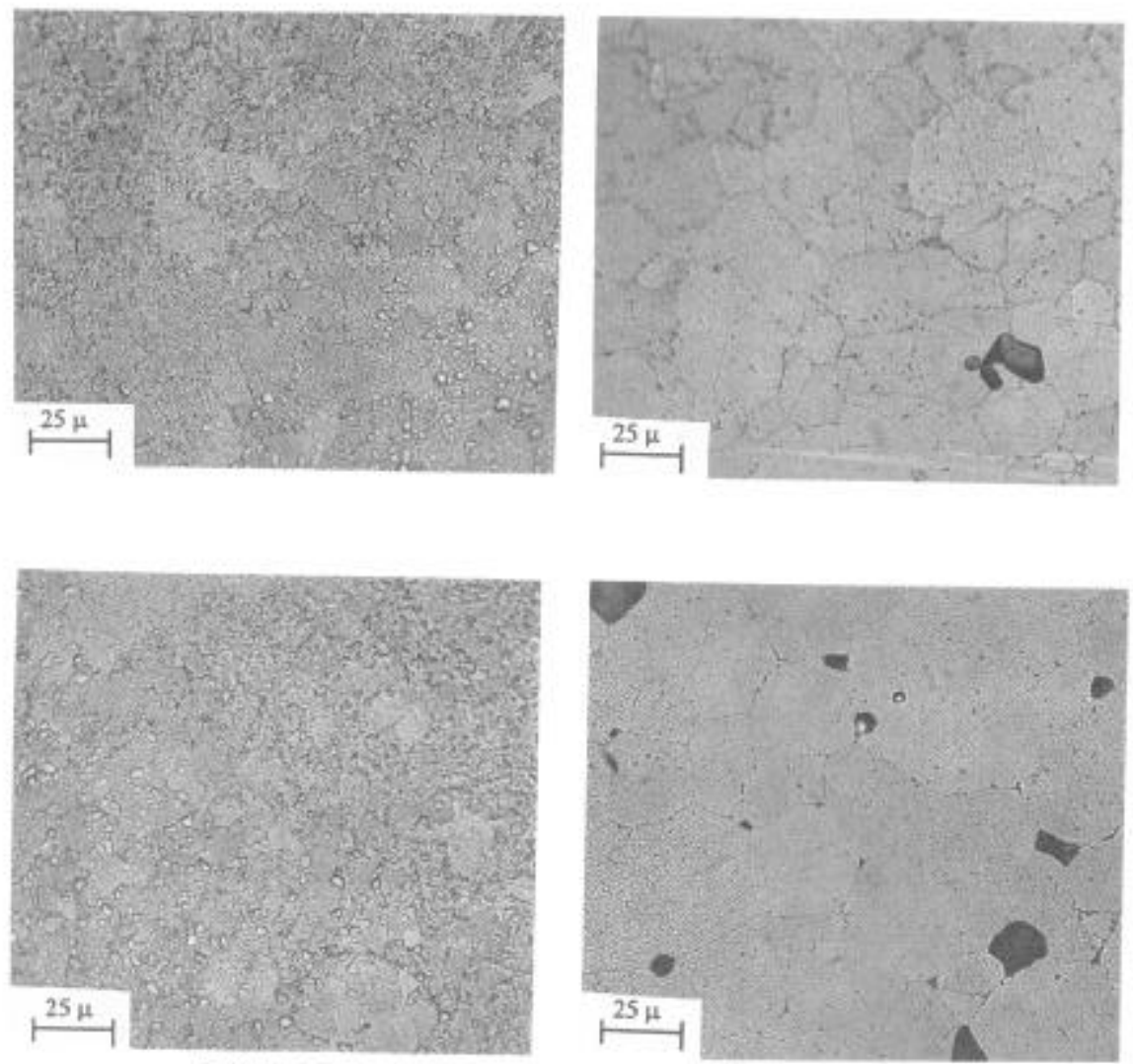

T-887, 6-KM4 (0.030B-0.040C): density change $0.60 \%$. left - as HIP'ed at $1175^{\circ} \mathrm{C}$, right - TIP exposure $1204^{\circ} \mathrm{C} / 4 \mathrm{hr}$

Figure 4: Representative micrographs of material with varying degrees of TIP. These micrographs were from selected runs from the DoE shown in Table 2.

Table 3: Atomization Parameter and TIP Response Data

\begin{tabular}{|c|c|c|c|c|c|c|c|c|c|c|c|c|c|c|c|c|c|c|c|}
\hline Atomize Aunf & $T-660$ & $T .850$ & T.e52 & $T-4051$ & T.e53 & $T .854$ & $7-661$ & T.958 & T.882 & T-883 & $T-8 B 6$ & T-aes & T.2as & T.887 & T-862 & T-6e9| & $T-890$ & T.891 & L982 \\
\hline Alloye & $1 . \mathrm{KMA}$ & $2-\mathrm{xum}$ & $3 \mathrm{KMAs}$ & 4-KMA & 5. KMM & $6 . \mathrm{KMM}$ & $7-\mathrm{kmes}$ & $\mathrm{KMM}$ & 6.KM4 & $4 \mathrm{KM4}$ & $6 \mathrm{kM4}$ & S-KM4 & O-KMA & O.KM4 & $2 \cdot \mathrm{KNMA}$ & $2-\mathrm{K} \times 4$ & $2-\mathrm{kMA}$ & $2-\mathrm{KMM}$ & KMA4 \\
\hline Purpoes & Exp-1] & Exp. 1 & Exp: 1 & Exp, 1 & Exe. 1 & Exp: 1 & Exp. 1 & Exp. 1 & -es51 & - 4854 & Dof & Dof & DoE & DoE & DoE & Dof & DoE & DoE & Fod \\
\hline Atomizing Gas & Ar & Ar & Ar & Af & Ar & Af & $\mathrm{N} 2$ & Ar & An & Ar & At & As & Ar & Ar & At & Ar & $A a$. & $\mathrm{An}_{\mathrm{n}}$. & An \\
\hline $\begin{array}{l}\text { Motal Flow } \\
\text { theimini }\end{array}$ & 3.1 & 16.3 & 13.5 & 7.1 & 14,3 & 30.8 & 13.2 & 26 & 11.5 & 11.5 & 27.8 & 3.5 & 2.6 & 16.7 & 18.e & 27,5 & 2.1 & 2.8 & nia \\
\hline Gos/Metal Ratio & 8. & 2.1 & 2.0 & 8.8 & 2.9 & 1.2 & 2.8 & 9.0 & 4.8 & 3.4 & 1.7 & 6.8. & 6.4. & 1.5 & 2.5 & 1.e & 8.0 & 0.1 & Nos \\
\hline $\begin{array}{l}\text { Penum Prasa. } \\
\text { (ther) }\end{array}$ & 23.8 & 21,8 & 18.7 & 37.4 & 30.6 & 30.6 & 34.0 & 23.1 & 37.4 & 30.6 & $\mathbf{3 3 . 6}$ & 23.5 & 23.8 & 22.1 & 30.0 & 31.3 & 17.0 & 23.8 & $\mathrm{~N} / \mathrm{m}$ \\
\hline $\begin{array}{l}\text { C fweight } \\
\text { percenti) }\end{array}$ & 0.015 & 0.040 & 0.065 & 0.040 & 0.040 & 0.040 & 0.040 & 0.030 & 0.040 & 0.040 & 0.040 & 0.040 & 0.040 & 0.040 & 0.040 & 0.040 & 0.040 & 0.040 & 0.000 \\
\hline $\begin{array}{l}B \text { (woight } \\
\text { percent) }\end{array}$ & 0.015 & 0.015 & 0.015 & 0.000 & 0.015 & 0.030 & 0.015 & 0.030 & 0.030 & 0.000 & 0.030 & 0.030 & 0.030 & 0.030 & 0.015 & 0.016 & 0.015 & 0.015 & 0.030 \\
\hline $\begin{array}{l}\text { POWOEA } \\
\text { SOUACE }\end{array}$ & CAD & COO & CAD & CRO & CAD & ono & CRO & CRO & cro & OnD & CAD & CAD & CAD & $\mathrm{CrO}$ & CHO & $C A D$ & CRD & CRD & wo \\
\hline$\frac{x-270}{x-400}$ & $\frac{n / d}{n / m}$ & $\frac{51.2}{40.1}$ & $\frac{64.6}{41.7}$ & $\frac{87.4}{75.8}$ & $\frac{n .9}{66.5}$ & $\frac{43.4}{310}$ & 67.5 & 87.1 & 725 & 56.5 & 33.7 & 87.7 & nio & 39.9 & 51.3 & 39.4 & 801 & no & $n / 2$ \\
\hline$\frac{x-400}{x-270 i+400}$ & $n / d$ & $\begin{array}{l}11,1 \\
11.1\end{array}$ & 129 & 115.6 & $\begin{array}{l}68.5 \\
11.4 \\
1\end{array}$ & $\frac{33.0}{10.4}$ & $\frac{55.9}{11.6}$ & $\frac{72.0}{15.1}$ & $\frac{01.0}{120}$ & $\frac{430}{140}$ & 22.7 & $\frac{71.2}{10.5}$ & nis & $\frac{20}{10.9}$ & 36.2. & 26.5 & 60.1 & 50.2 & $n / 2$ \\
\hline$\frac{8-270 i+400}{\$ \text { Porous }}$ & & & & & & & 11.5 & 15.1 & 1200 & 10.0 & 11.0 & 16.6 & Nol & 10,1 & 15.1] & 12.9 & 20.0 & 17.9 & $n / 2$ \\
\hline$\frac{(-270 /+325)}{3 \text { Porous }}$ & 19.3 & 35.2 & 45.3 & 27.3 & 16.2 & 44.7 & 11.1 & 9.7) & 12.1 & 14.7 & 24.3 & 17.4 & 10.8 & 30.8 & 30.0 & 19.5 & 10.7 & 131 & 5.2. \\
\hline$\frac{(-325)+400)}{\text { EXTRUSIONS }}$ & 2.5 & 20.6 & 26.6 & 25.1 & 13.1 & 25.2 & 18.7 & 2. & 20.1 & 14.3 & 29.1 & 24.7 & 11.3 & 28.0 & 24.0 & 10.5 & 7.4 & 9.6 & 5.1 \\
\hline $\begin{array}{l}\text { As Extruded } \\
\text { Denvity (plec) }\end{array}$ & c.0189 & 8.0100 & 8.0290 & 8.0304 & 8.0096 & 8.0063 & 8.0272 & 8.0203 & & & & & & & & & & & \\
\hline $\begin{array}{l}\text { Extruaion TIP } \\
\text { Level }\end{array}$ & $-2.20 x$ & $-2.20 x$ & $-0.10 x$ & $-0.11 \%$ & $-2.30 x$ & $-5.60 \%$ & $0.04 x$ & $-0.10 \times$ & & & & & & & & & & & \\
\hline$\frac{\text { HIP CANS }}{\text { As Hod od }}$ & & & & & & & & & & & & & & & & & & & \\
\hline $\begin{array}{l}\text { As HEP od } \\
\text { Density (g/oc) }\end{array}$ & 8.03336 & 8.0278 & 8.0290 & 8.0317 & 8.0321 & 1.0259 & & 7.8296 & 8.0261 & 7,8003 & 8.0245 & 8.0310 & 8.0272 & 8.0245 & 8.0264 & 8.0271 & 8.0201 & 8.0266 & 8.0200 \\
\hline $\begin{array}{l}\text { HIP Can TiP } \\
\text { Level }\end{array}$ & $0.12 x$ & $-0.18 x$ & $-0.17 x$ & $-0.10 \times 1$ & $0.27 \times$ & $-0.70 \times$ & & $-0.39 x$ & $-0.68 \times$ & $0.08 \mathrm{~s}$ & $-0.30 \times 1$ & $-0.38 \mathrm{x}$ & $-0.31 \times$ & $-0.00 \times$ & $-0.16 \%$ & $-0.13 \times$ & $-0.08 \%$ & $-0.10 *$ & $-0.28 x$ \\
\hline
\end{tabular}


by following the somewhat chronological outline discussed below.

The initial observation of high TIP levels was somewhat of a surprise. The first indication of high TIP levels in some of the extrusions was observed in a microstructure versus chemistry vs. thermal exposure study. Samples from each of the alloys were exposed to temperatures of $1163^{\circ} \mathrm{C}, 1171^{\circ} \mathrm{C}, 1179^{\circ} \mathrm{C}, 1188^{\circ} \mathrm{C}$, $1196^{\circ} \mathrm{C}$, and $1204^{\circ} \mathrm{C}$ for four hours. Representative micrographs are shown in Figure 4. These are compared to as-HIP'ed micrographs to show that consolidation was not the problem good can integrity allowed full consolidation to be achieved in both HIP \& extrusion. The porosity formed during the subsequent thermal exposure. After this initial study, $1204^{\circ} \mathrm{C} / 4 \mathrm{hr}$ was chosen as the standard TIP evaluation heat treat cycle.

An early assessment using only the runs shown in Table 1 showed that $6 \mathrm{KM} 4$, with the worst TIP, had the highest melt flow rate, coarser size distribution, and low G/M, while $4 \mathrm{KM} 4$, with the best TIP, had low flow rate, finer size distribution, and a high G/M.

An additional comparison was made to an available productionscale KM4 extrusion, made with $0.030 \mathrm{~B}-0.030 \mathrm{C}$ material, E462. This extrusion was produced from -140 mesh Cameron Powder Systems powder, extruded at Cameron Forge (both are now part of Wyman-Gordon) for the Dual Alloy Disk (DAD) program. The TIP values reported for E462 by Cameron were 0.23 to $0.26 \%$. This compared favorably to a TIP level measured at GE CRD of $0.28 \%$ using a small HIP can of archived powder from the same heat (L-982). Overall for the DAD extrusions, the four heats, representing four chemistries, with boron levels above $0.030 \mathrm{w} / \mathrm{o}$ had an average TIP response of $0.24 \%$, while the two heats with boron levels around $0.015 \mathrm{w} / \mathrm{o}$ had an average TIP response of $0.19 \%^{2}$.

These initial trends began to suggest that boron impacted TIP. However, the apparent scatter in the initial data suggested that other factors were playing a role on overall porosity. The atomization runs performed at this point did not allow complete separation of chemistry impacts from atomization parameter impacts. Additional runs were made to produce the core Designed Experiment (DoE) shown in Table 2 to better identify these trends.

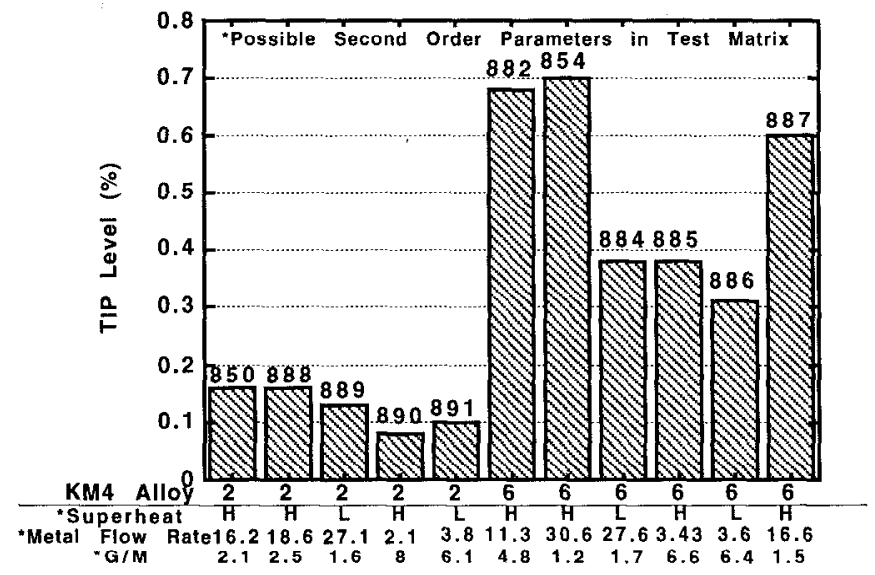

Figure 5: Summary of results for overall experiment. A clear scparation between high boron heats (KM4 alloy 6) and low boron heats (KM4 alloy 2) versus TIP level was obvious.
The first step of the DoE analysis, scatter plots, further established what controlled porosity. The overall results are summarized in Figure 5, with the complete data presented in Table 3. The most obvious trend was the influence of boron level on TIP. The other variables of superheat, flow rate, and Gas:Metal (G:M) ratio also showed trends. Each of the parameters will be discussed in detail below.

In general the porosity could be classified into two types. The first was porosity in the loose powder particles, referred to as "percent (\%) porous". This was measured by the loose powder technique. The second was classical Thermally Induced Porosity (TIP), produced after consolidated samples were exposed to elevated temperature. This was measured by the density change technique. Overall, alloy chemistry trends tended to correlate with TIP porosity, while the atomization method trends tended to correlate with the percent porous powder porosity.

The most obvious trend was for boron. Boron strongly influenced TIP porosity (Figure 6). The relationship appeared to be non-linear. For the heat with 0.000 boron, the TIP porosity density change was less than $0.1 \%$, while for heats with 0.015 boron, the TIP porosity density change data fell between about $0.28 \%$ and $0.18 \%$, and for heats with 0.030 boron, the TIP porosity density change data fell between $0.7 \%$ and $0.3 \%$. The $0.015 \mathrm{~B}$ and $0.030 \mathrm{~B}$ levels were markedly different. Metallography showed that the higher boron corresponded to increased amount of incipient melting (Figure 7). The boron apparently promoted TIP formation by weakening of grain boundary triple points. Boron did not appear to have an effect on loose powder porosity (Figure 8).

In contrast to boron, carbon had no apparent effect on either TIP porosity or loose powder percent porous.

The level of superheat showed a weak trend against both TIP porosity and loose powder percent porous, with higher superheat tending to increase porosity. This is shown in Figures 9 and 10.

The as-atomized size distribution of the powder showed a strong trend against percent porous, with finer powder resulting in reduction in percent porous powder (Figure 11). However, the size distribution showed a weaker trend against as-HIP density (Figure 12), with finer size distributions resulting in higher asconsolidated densities.

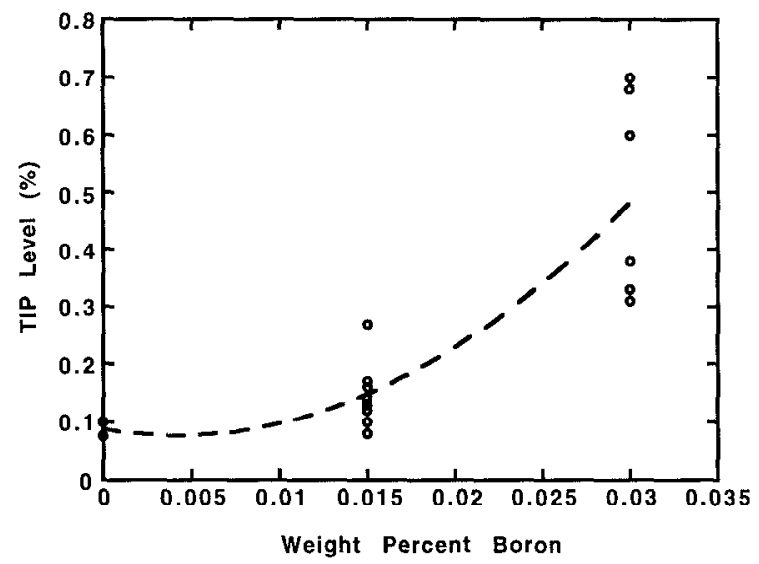

Figure 6: Influence of boron on TIP level. A sharp increase in TIP occurred as boron increased to 0.030 weight percent. 


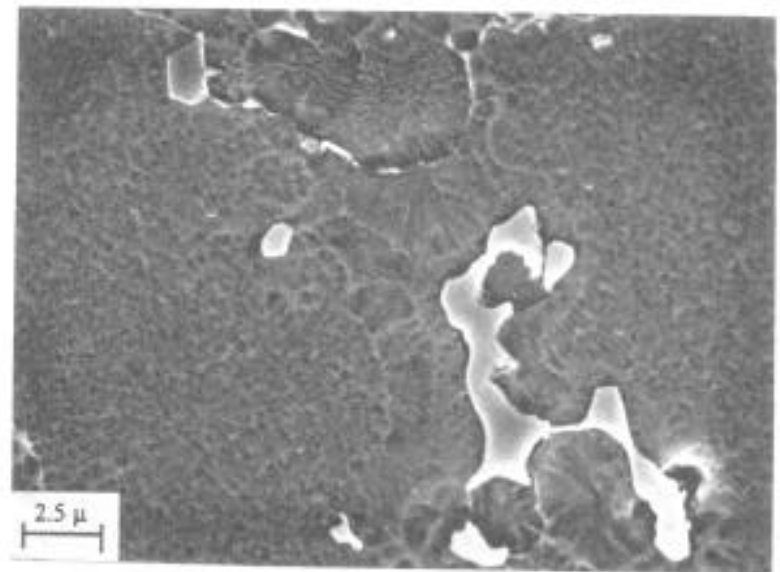

Figure 7: Micrograph showing incipient melting and pore formed at triple point. The boron apparently caused localized melting of the material.

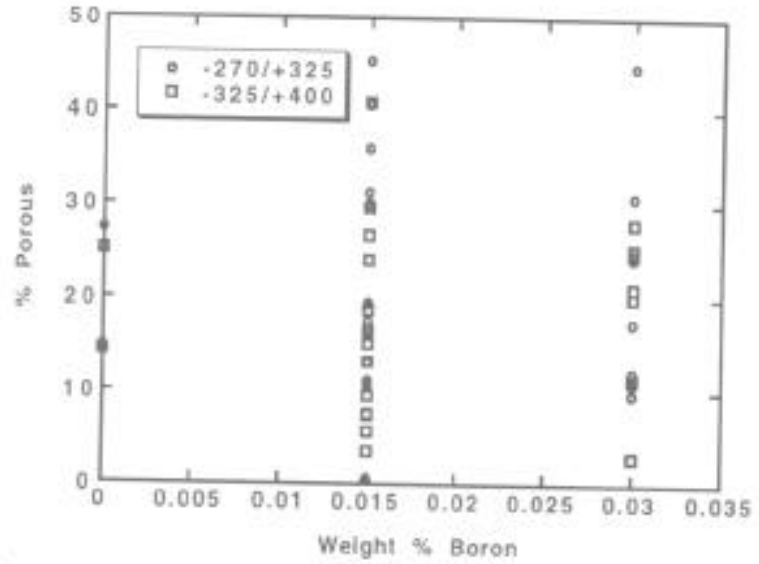

Figure 8: Boron had no statistical impact on loose powder porosity ( $\%$ porous). This result was consistent for both fine $(-325 /+400$ mesh $)$ and somewhat coarser $(-270 /+325$ mesh $)$ size fractions.

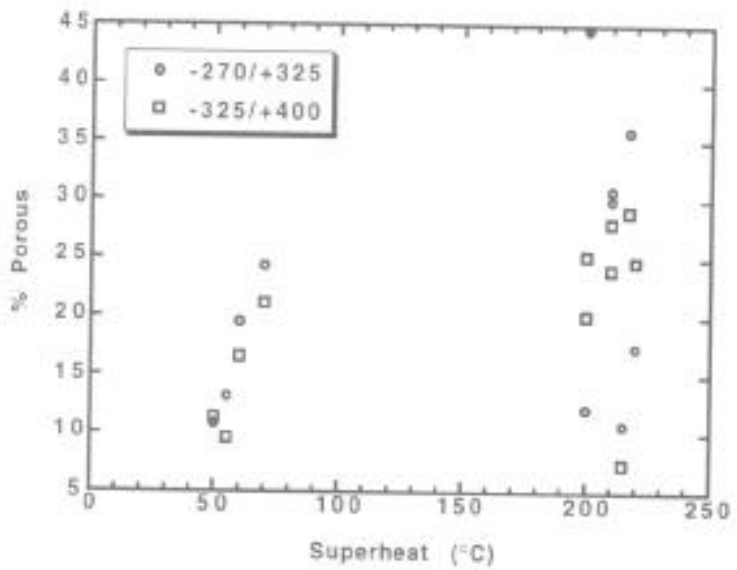

Figure 9: Increased superheat promoted a slight increase in loose powder porosity ( $\%$ porous). Only the data from the L8 Designed Experiment (Table 2) are shown since these were the runs with controlled superheat variations.

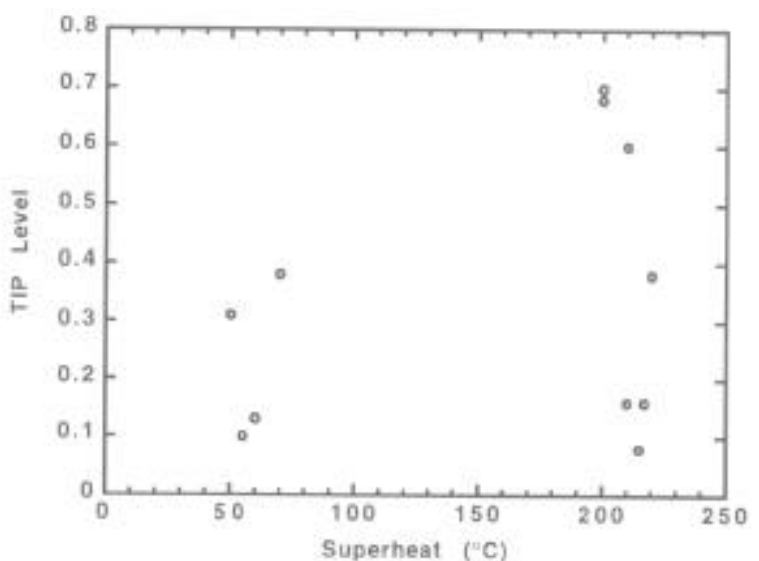

Figure 10: Increased superheat also promoted an increase in TIP level of consolidated material. As in Figure 9, only the data from the L8 Designed Experiment (Table 2) are shown.

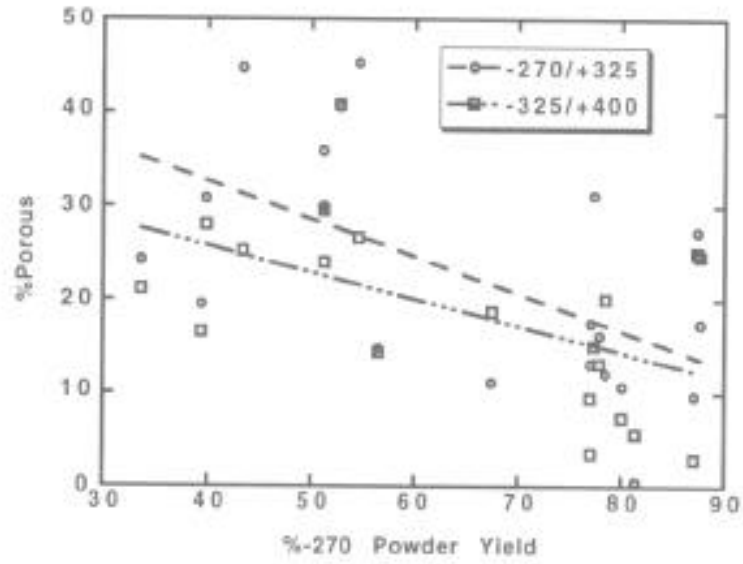

Figure 11: Relationship between relative fineness of powder heats and loose powder porosity. Heats with a finer size distribution (greater percentage of fine powder) showed a reduction in loose powder porosity.

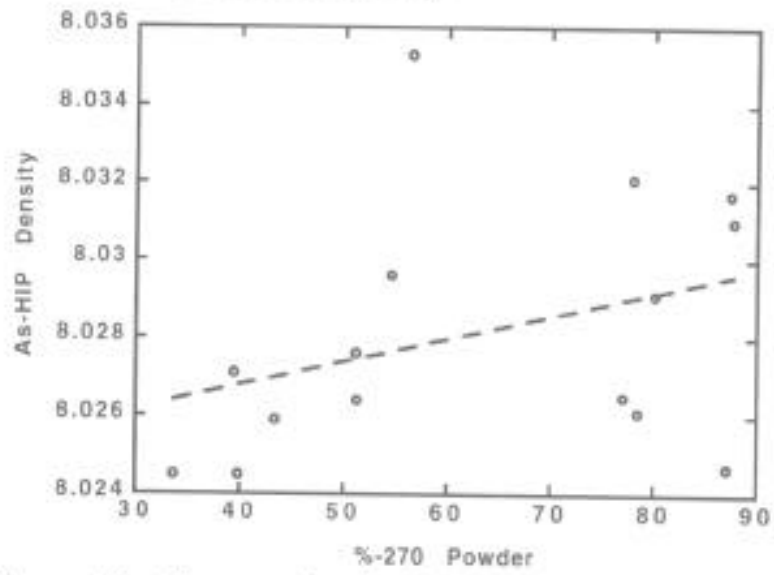

Figure 12: Finer powder distributions promoted a higher as consolidated density (and reduced TIP). 
The metal flow rate appeared to have more influence than superheat on loose powder porosity. Metal flow rate showed a strong trend, with higher flow rate increasing porosity (Figure 13). The relationship between metal flow rate and TIP porosity was much less clear, although the data suggested that higher flow rate correlated weakly with higher TIP porosity (Figure 14). The influence of metal flow rate was related to mesh size, as the metal flow rate strongly impacted the mesh size distribution, with finer powder resulting from lower flow rate (Figure 15). Thus low flow rate promoted higher production yields of fine powder.

Metal flow rate is also related to the gas/metal ratio (G/M), so the trends observed for $\mathrm{G} / \mathrm{M}$ were expected based on the flow rate trends. Increased $\mathbf{G} / \mathbf{M}$ ratio was associated with lower porosity, with a strong relationship against porous powder (Figure 16), but no clear relationship with TIP porosity (Figure 17).

The nitrogen atomized heat, 7-KM4, was very low in porosity, and actually showed a very slight density increase after the TIP exposure. This was probably within test technique tolerance and

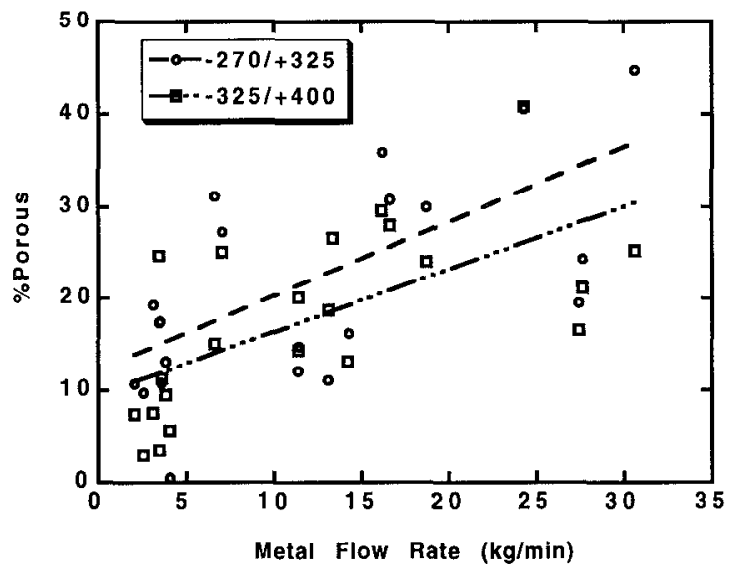

Figure 13: Relationship between metal flow rate and loose powder porosity. Higher flow rates led to significant increases in porosity.

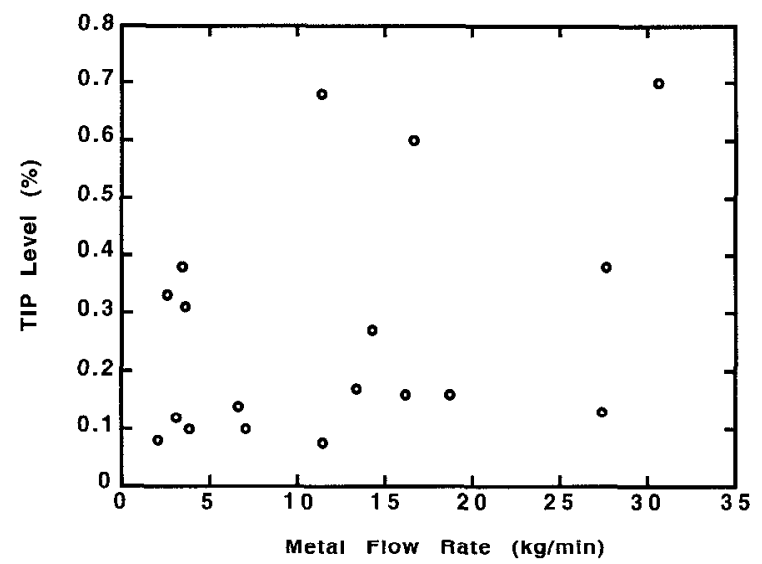

Figure 14: Relationship between metal flow rate and TIP level, showing a weak tendency for increased TIP with increased flow rate. Only the data from the L8 DoE are included.

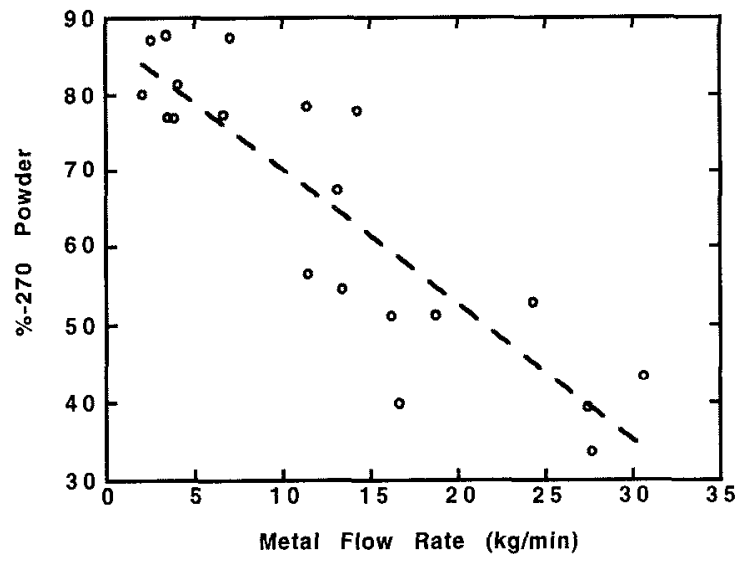

Figure 15: A very strong relationship between flow rate and yield of fine powder was observed. Low flow rates were preferred for finer powder distributions.

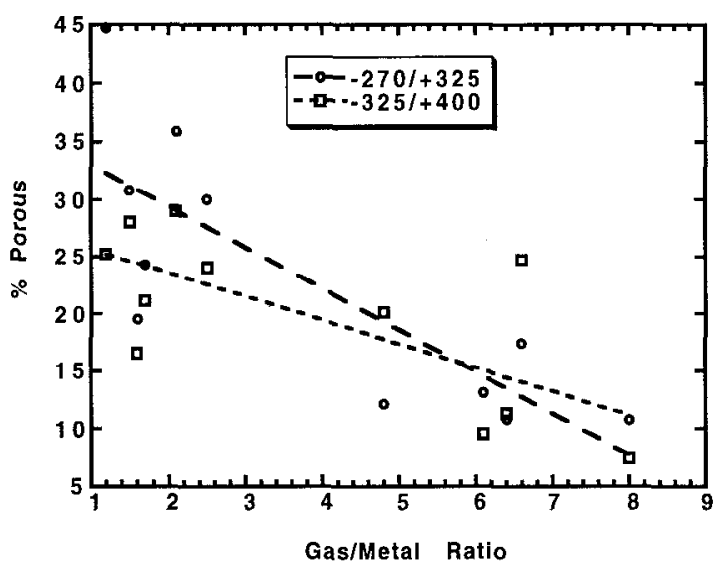

Figure 16: Relationship between gas:metal (G.M) ratio and loose powder porosity. Higher values of G:M reduced the amount of porosity. Note that metal flow rate is related to G:M so the trends between Figure 15 and Figure 16 are understandable. Only the runs from the L8 DoE (Table 2) are included.

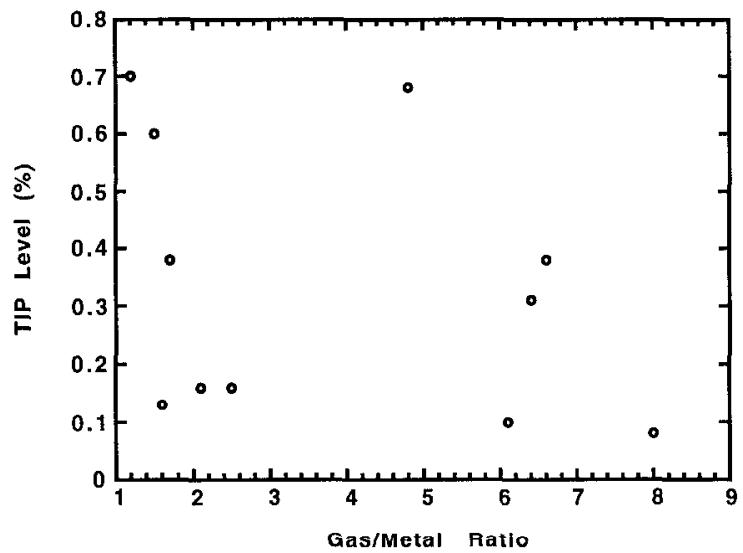

Figure 17: Gas:metal ratio had no real impact on TIP level, in contrast to its impact on loose powder porosity (Figure 16). 
indicated essentially zero tip. No pores were observed metallographically in this alloy while they were readily observable in the argon-atomized alloys.

The next step of DoE analysis, tests for statistical significance, was performed using standard techniques'. The numerical analysis largely confirmed the trends observed from the effect scatter plots discussed above. Statistically significant relationships were found between boron and TIP (Figure 6), flow rate and percent fine powder (Figure 15), and flow rate and percent porous (Figure 13). Although many of the other trends were not rigorously shown to be statistically significant, this type of experiment has a high standard error and the trends identified from the scatter plots can still suggest potential approaches to achieve process improvements.

LCF tests were done at $649^{\circ} \mathrm{C}$ and $0.80 \%$ strain (Table 4). The alternating pseudostress values varied slightly due to experimental differences in establishing the modulus and initial strain range. The material chosen for testing represented the alloys from the initial extrusions likely to have the lowest porosity: alloys 3-KM4 (0.015B-0.065C), 7-KM4 (0.015B-0.040C-nitrogen atomized), and 4-KM4 (0.000B-0.040C). The lives were compared to results from the baseline $0.030 \mathrm{~B}-0.030 \mathrm{C}$ composition 2 as shown in Figure 18. The 0.015B material was definitely improved relative to the $0.030 \mathrm{~B}$ baseline, but the alloy with no boron showed a lower average life than the other two alloys ( 44717 average cycles for 4-KM4 compared to 67421 average cycles for 3-KM4 and 68410 for 7-KM4). The comparisons with the $0.030 \mathrm{~B}$ baseline were somewhat compromised by the use of different atomization sources, so that the ceramic inclusion content would be expected to vary, but the $0.030 \mathrm{~B}$ material displayed low lives due to pore initiation sites and the reduced boron definitely reduced this tendency. The differences between the $0.000 \mathrm{~B}$ and $0.015 \mathrm{~B}$ heats in the present study were small relative to the reduced lives (Figure 18 ) shown by the $0.030 \mathrm{~B}$ data $^{2}$.

\section{DISCUSSION}

The impact of boron was an important result as it suggests a means to widen the heat treat window of advanced P/M disk alloys. Many of these alloys have solvus temperatures above

Table 4: LCF Test Results

\begin{tabular}{|c|c|c|c|c|}
\hline Altor & $\begin{array}{r}\text { Test } \\
S / N\end{array}$ & $\begin{array}{c}\text { Alternat ing } \\
\text { Pseudostres } \\
\text { (MPa) }\end{array}$ & Nf & $\begin{array}{c}\text { Average } \\
\text { Nf }\end{array}$ \\
\hline $\begin{array}{c}3-\mathrm{KM4} \\
(0.015 \mathrm{~B}-0.065 \mathrm{C})\end{array}$ & $\begin{array}{l}1-02 \\
2-02 \\
3-02\end{array}$ & $\begin{array}{l}714.3 \\
717.8 \\
719.8 \\
\end{array}$ & $\begin{array}{l}69457 \\
42617 \\
90191\end{array}$ & 67421 \\
\hline $\begin{array}{c}4-1014 \\
(0.0008-0.040 \mathrm{C})\end{array}$ & $\begin{array}{l}4-02 \\
5-02 \\
6-02\end{array}$ & $\begin{array}{l}722.6 \\
714.3 \\
730.9\end{array}$ & $\begin{array}{l}40507 \\
61894 \\
31750\end{array}$ & 44717 \\
\hline $\begin{array}{c}7-\mathrm{kM4} \\
(0.015 \mathrm{~B}-0.040 \mathrm{C} \\
\text { nitrogen })\end{array}$ & $\begin{array}{l}7-02 \\
8-02 \\
9-02 \\
\end{array}$ & $\begin{array}{l}722.6 \\
725.3 \\
722.6\end{array}$ & $\begin{array}{l}78569 \\
50234 \\
76429 \\
\end{array}$ & 68410 \\
\hline \multicolumn{5}{|c|}{$\begin{array}{l}\text { Motes: 1) all tests conducted at } 649 \mathrm{C}, 0.80 \mathrm{x} \text { aim strain range } \\
\text { 2) alternoting pseudostress }=\frac{\text { (modulus })(\sin \text { rain range) }}{2}\end{array}$} \\
\hline
\end{tabular}

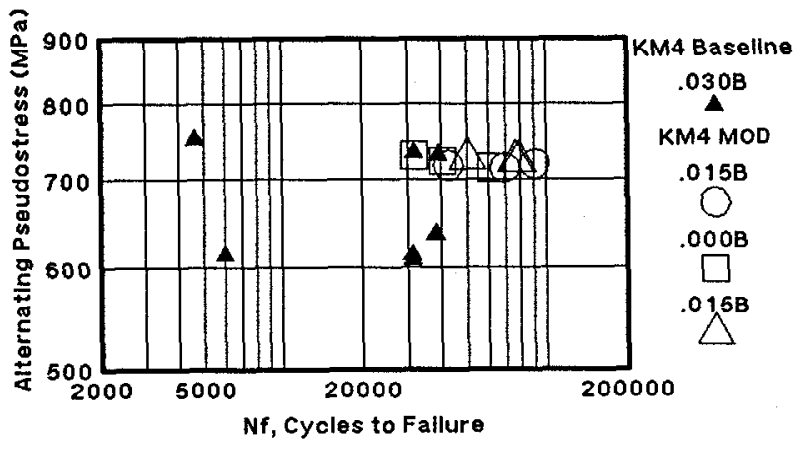

Figure 18: Low Cycle Fatigue (LCF) results for KM4. Data from $0.030 \mathrm{~B}$ baseline composition ${ }^{2}$ are compared to heats with reduced boron. The reduced boron led to increased life and reduced scatter.

$1170^{\circ} \mathrm{C}$, yet have added boron content to improve fatigue crack growth $^{6}$. The alloys thus show TIP formation concurrent with boride melting as low as $1193^{\circ} \mathrm{C}$. This heat treatment window may be too tight for reliable production. This study suggests that added boron to improve crack growth properties must be balanced against a low boron level desirable to improve producibility and improve LCF capability.

The results in terms of boron impact are also consistent with a study conducted on alloy APK1, essentially Astroloy ${ }^{7}$. In that study, boron was varied from 0.017 to 0.025 weight percent. Using Differential Thermal Analysis (DTA), equations for the solidus and $\mathrm{M}_{3} \mathrm{~B}_{2}$ solvus temperatures were determined:

$$
\begin{aligned}
& \text { Solidus in degrees } C=1285-0.26 \mathrm{~B}(\mathrm{~B} \text { in ppm) } \\
& \mathrm{M}_{3} \mathrm{~B}_{2} \text { solvus in degrees } \mathrm{C}=1255-0.20 \mathrm{~B}(\mathrm{~B} \text { in ppm) }
\end{aligned}
$$

For $0.015(150 \mathrm{ppm})$ boron these equations predict a solidus temperature of $1246^{\circ} \mathrm{C}$ and a boride solvus of $1125^{\circ} \mathrm{C}$. For 0.030 (300 ppm) boron these equations predict a solidus temperature of $1206^{\circ} \mathrm{C}$ (a $40^{\circ} \mathrm{C}$ drop) and a boride solvus of $1195^{\circ} \mathrm{C}$ (a $30^{\circ} \mathrm{C}$ drop). If these equations directly applied to KM4, increasing the boron from 0.015 to 0.030 would be predicted to produce both incipient melting of the alloy itself and the dissolution of the boride phase, which probably also promotes local grain boundary incipient melting, for typical solution temperatures of 1190 $1200^{\circ} \mathrm{C}$ and the TIP temperature of $1204^{\circ} \mathrm{C}$.

Since excessive boron promotes incipient melting and a high level of measured TIP density change, reduction of boron is attractive. The minimum level to insure adequate properties must be established. Previous researchers ${ }^{8}$ have claimed that amounts above the solubility limit are of little value. At a grain size of 10 microns ( ASTM 11), only 0.001 w/o boron was calculated as the minimum level. In the present study the very slightly lower LCF results of $4-\mathrm{KM} 4(0.000 \mathrm{~B})$ suggested that even at relatively time-independent conditions of $649^{\circ} \mathrm{C}, 30 \mathrm{cpm}$, elastic LCF cycling, complete omission of boron had some effect. Further work focused on property testing is needed to establish an optimum boron content to balance TIP vs. high temperature performance. 
The potential of alloy chemistry to influence porosity has been noted by others. An existing patent ${ }^{9}$ claims that the addition of trace amounts of $\mathrm{Mg}$ or $\mathrm{Ca}$ functioned as activating agents which reduced TIP. The activating agents worked by rapidly diffusing to the surface of the metal powder particles and attracting oxygen.

The boron influence was stronger for TIP porosity than for the as-atomized loose powder porosity. The TIP porosity mechanism seems related to local weakening of the material allowing the residual entrapped gas to form a pore. Apparently the incipient melting mechanism is not kinetically likely to occur during droplet solidification and the powder solidification behavior is not influenced by boron content.

The fact that low melt flow rates increased yield and tended to correlate with reduced TIP is comforting as both results are desirable and the superalloy powder metal suppliers are working to improve yields. Reduced flow rate, low superheat, and high gas/metal ratio (to reduce powder size) all promoted lower porosity and tended to have greater impact on the as-solidified loose powder porosity relative to the impact of boron. The loose powder porosity mechanism appears related to the droplet formation. Apparently these atomization events influenced the stream behavior and how the droplets were formed. The lack of a strong impact of atomization chamber pressure is surprising. Other researchers ${ }^{10}$ have held that reduced pressure during atomization reduced entrapped argon content. The details of the atomization condition in that study are unknown. The lack of apparent impact of pressure in the present study may reflect the fact that it was not deliberately varied in a controlled manner (or was not varied to a sufficient level to observe the effect). Also the short run time and subscale nature of the CRD atomizer mean that the pressure may not reach equilibrium during the runs.

As a final comment, this study supports the power of Designed Experiment approaches to solve engineering problems. In the initial runs atomization parameters were allowed to vary with the assumption the final properties would not be affected. A DoE was required to eventually sort through the various factors impacting porosity. The initial experiment could still have been made with lower risk if the variation had been systematic and the alloy chemistry variation was "blocked" appropriately, essentially a Designed Experiment. This was the approach taken for the third group of powder heats which when completed allowed very clear identification of trends. It is recommended that all experiments be blocked against both deliberately varied parameters and potential shifts in equipment-related or environmentally-influenced factors.

\section{CONCLUSIONS AND RECOMMENDATIONS}

1. Porosity could be classified into two types: porosity in the loose powder particles, referred to as "percent (\%) porous"; and Thermally Induced Porosity (TIP), produced after consolidated samples were exposed to elevated temperature. TIP porosity was strongly influenced by alloy chemistry while loose powder porosity was most influenced by atomization parameters.

2. Boron strongly impacted the TIP porosity. The relationship appeared to be non-linear, with sharply increasing porosity for
0.030 boron. Boron did not have any apparent effect on the percent porous loose powder. The higher boron corresponded to increased amount of incipient melting, apparently promoting TIP formation by weakening of grain boundary triple points.

3. Several atomization parameters influenced loose powder porosity. Higher superheat, coarser powder size distribution, increased metal flow rate, and reduced G:M ratio all correlated with increased porosity.

4. Two important measurement techniques, measurement of porosity in loose powder (percent porous), and careful density measurements before and after TIP exposure, were key in obtaining useful conclusions.

5. Low Cycle Fatigue (LCF) testing results indicated that a reduction in boron from 0.030 to 0.015 or below weight percent had a beneficial impact on life, and was correlated with reduced severity of crack initiation due to TIP.

\section{ACKNOWLEDGMENTS}

The support of GE Aircraft Engines colleagues is appreciated, including technical guidance from Dan Krueger and the sample processing provided by Ron Tolbert and Bill Brausch. Swami Ganesh of GE Power Generation also provided key technical input to this program. GE Corporate Research and Development personnel also assisted with this project, notably Steve Miller, Larry Wojcik, Paul Dupree, and Paul Martiniano. John Hughes processed the extrusions at GE CRD while Don Weaver, Bill Konkel, and Noshir Bhathena were responsible for the Cameron extrusions (Cameron is now a part of Wyman-Gordon).

\section{REFERENCES}

1. D. D. Krueger, J. F. Wessels, and Keh-Minh Chang, U. S. Patent 5,143,563, General Electric Co., September 1, 1992.

2. S. Ganesh et. al., "Advanced Technology for $1500^{\circ} \mathrm{F}$ Turbine Disk Materials (Dual Alloy Disk) Program", Final Report, Contract N00140-89-C-WC14, Sept. 30, 1994.

3. S. A. Miller and R. S. Miller, "High Speed Video and Infrared Imaging of Close-Coupled Gas Atomization", in Powder Metallurgy in Aerospace, Defense, and Demanding Applications, ed. by F. H. Froes, Metal Powder Industries Federation, Princeton, New Jersey, 1993.

4. P. L. Dupree, T. F. Sawyer, and M. G. Benz, "Improved Method For Measuring Relative Density", GE Corporate Research \& Development Report 90CRD240, May 1991.

5. R. H. Lochner and J. E. Matar, Designing For Quality, American Society for Quality Press, Milwaukee, Wisconsin, 1990.

6. J. Gayda. T. P. Gabb, and R. V. Miner, "Fatigue Crack Propagation of Nickel-Base Superalloys at $650^{\circ} \mathrm{C} "$, Low Cycle Fatigue, ASTM STP 942, ed. by H. D. Solomon et. al., American Society for Testing and Materials, Philadelphia, PA, 1988, 293309. 
7. G. A. J. Hack and J. W. Eggar, "Comparison of Nimonic Alloy APK1 Consolidated at HIP Temperatures Above and Below the Boride Solvus", in Powder Metallurgy Superalloys: Aerospace Materials for the 1980's, Metal Powder Report Conference. Volume 2, 18-20 November 1980, Zurich, pp. 20.120.50 .

8. T. J. Garosshen, T. D. Tillman, and G. P. McCarthy, "Effects of $\mathrm{B}, \mathrm{C}$, and $\mathrm{Zr}$ on the Structure and Properties of a P/M Nickel Base Superalloy", Met. Trans. 18A, 1987, pp. 69-77.

9. J. M. Larson, I. S. R. Clark, and R. C. Gibson, "Porosity Reduction in Inert-Gas Atomized Powders", U. S. Patent 4,047,933, September 13, 1977.

10. R. J. Siddall, "Atomization into a Chamber Held at Reduced Pressure", U. S. Patent. 4,233,062, November 11, 1980. 